\title{
Creating Pro-Environmental Residents: The role of environmental knowledge
}

\author{
Saripah Abdul Latif a, Mohd Shukri Omara, \\ Yeop Hussin Bidi a , Zainudin Awang ${ }^{b}$ \\ a Faculty of Business Management \\ ${ }^{b}$ Faculty of Mathematics and Science Computer \\ Universiti Teknologi MARA, Kota Bharu 15050, Malaysia \\ saripah@kelantan.uitm.edu.my
}

\begin{abstract}
An exorbitant rate of resource consumption has created a negative impact on the urban environment. If urban residents fail to behave pro-environmentally, a gradual but sure deterioration of the environment is due in the near future. This study examines the relation between environmental knowledge and pro-environmental behaviour of the residents, with environmental values as the mediator. Survey data was gathered from residents of five large urban neighborhoods in Malaysia. Structural equation modeling is used to analyse the data. Conclusively, environmental knowledge affects the inculcation of environmental values in the residents of urban areas, which in turn affects their pro-environmental behaviour.
\end{abstract}

Keywords: Pro-environmental behaviour; environmental knowledge; environmental values; quality of life

eISSN: 2398-4295 @ 2016. The Authors. Published for AMER ABRA by e-International Publishing House, Ltd., UK.. This is an open access article under the CC BY-NC-ND license (http://creativecommons.org/licenses/by-ncnd/4.0/). Peer-review under responsibility of AMER (Association of Malaysian Environment-Behaviour Researchers), ABRA (Association of Behavioural Researchers on Asians) and $c E-B s$ (Centre for EnvironmentBehaviour Studies), Faculty of Architecture, Planning \& Surveying, Universiti Teknologi MARA, Malaysia.

https://doi.org/10.21834/ajbes.v1i2.29 


\subsection{Introduction}

A rising quality of life with an exorbitant rate of resource consumption has created an unintended and negative impact on the urban environment. The huge amount of waste generated is far beyond the handling capacities of urban governments and agencies. Past researches showed three key trends in the issue of household waste management increase in volume of waste generated by urban residents; change in the quality of waste generated; and the disposal method of waste collected. Promoting the implementation of urban residents' sustainable consumption behavior has become a real challenge to city managers. The city's environmental protection depends on two aspects, the first is sustainable production of firms; the second is residents' pro-environmental behaviour ( $\mathrm{Hu}$, Dong and Yang, 2013). If urban residents fail to behave pro-environmentally, a gradual but sure deterioration of the environment is due in the near future. Then, the quality of life of urban societies itself will be at stake. In sequence to that, the achievement of the economic, social and environmental sustainable development of the nation at large will be hindered. As a developing country, Malaysia is being challenged hugely for its effort in becoming a sustainably developed country. Some examples of environmental issues that need to be managed by Malaysian government are urban air quality, river water quality, deforestation, household wastes and hazardous wastes from the industries. Accordingly, various policies and strategies are currently being developed and implemented by the government in order to ensure sustainable development (Saripah,Mohd Shukri, Yeop Hussin and Zainudin, 2012).

Kollumuss \& Agyeman (2002) described pro-environmental behaviour as a behaviour that consciously seeks to minimize the negative impact of one's action on the natural and built environment (example minimize resource and energy consumption, use of non-toxic substances, reduce waste production and including recycling behaviour). It involves consciously applying an environmentally sound and socially responsible ethic to lifestyle choice (Akpan et al, 2003). Pro-environmental behaviour also involves actions taken to reduce one's ecological footprint. An ecological footprint is a calculation of the land area required to support a particular lifestyle in terms of resources and wastes (Flint, 2001 in Akpan et al, 2003). It would not be easy for every individual to directly measure his or her ecological footprint, however it is assumed that reducing water and energy use, reducing waste by reuse and recycling and adopting alternative modes of transportation are directly connected to reducing one's ecological footprint. Other terms found in the literature that are included under the rubric of pro-environmental behaviour are "environmentally responsible behaviour" and "sustainable behaviour".

The commonly accepted fact is without adequate knowledge of the factors that lead people to participate in recycling, it is very difficult to develop effective and sustainable policies (Schultz et al, 1995 in Clay, 2005 in Saripah, Yeop Hussin and Zainudin 2013). A question arises here. If we improve environmental knowledge, will it increase proenvironmental behaviour? 
Saripah et al (2013), stated that environmental education effort aimed at both the public and at students should be emphasized by the city managers and the government. They further suggested that environmental education could be embedded in the school syllabus, from as early as pre-school level, whilst city managers may organize periodical anti-littering campaigns for the public. This is to increase the awareness toward and to inculcate values of the environment among the residents. Once the residents have the environmental values inculcated in them, supposedly they would behave pro-environmentally.

This study examines the relation between environmental knowledge and proenvironmental behavior of the residents in urban areas, with environmental values as the mediator. The first objective of the study is to determine the causal relationship between environmental knowledge and pro-environmental behaviour. Another objective is to enlighten the mediating effect of environmental values between environmental knowledge and pro-environmental behaviour.

\subsection{Literature Review}

The question of what shapes pro-environmental behavior is such a complex one. It is believed that variables such as demographics, external factors (e.g. institutional, economic, social and cultural) and internal factors (e.g. motivation, pro-environmental knowledge, awareness, values, attitudes, emotion, locus of control, responsibilities and priorities) do have some effect on pro-environmental behavior on the main literatures reviewed (Kollmuss and Agyeman, 2002). Therefore, both environmental knowledge and environmental values are internal factors according to Kollmuss and Agyeman. They further added that although numerous theoretical frameworks have been developed to explain the gap between the possession of environmental knowledge and environmental values, and displaying proenvironmental behaviour, no definitive explanation has yet been found.

Early models of pro-environmental behaviour was based on a linear progression of environmental knowledge leading to environmental awareness and concern (attitude), which in turn was thought to lead to pro-environmental behaviour. These rationalist models assumed that educating people about environmental issues would automatically result in more pro-environmental behavior (.Kollmuss and Agyeman, 2002). These models from the early 1970s were soon proven to be wrong. Ajzen and Fishbein (1980) in their Theory of Planned Behaviour tried to address the measurement discrepancies for attitudes and behaviour. They pointed out that in order to find a high correlation between attitude and behavior the researcher has to measure the attitude of that particular behaviour (.Kollmuss and Agyeman, 2002). Therefore, we cannot compare attitude toward climate change and recycling behaviour. Instead we should compare attitude toward recycling itself and recycling behaviour. Ajzen and Fishbein maintain that people are essentially rational, in that they make systematic use of information available to them. 
Later on in 1986, Hines, Hungerford and Tomera published their Model of Responsible environmental Behaviour, which was based on Ajzen and Fishbein's theory of planned behavior (Kollmuss and Agyeman, 2002). They found the following variables associated responsible pro-environmental behavior knowledge of issue, knowledge of action strategies, locus of control, attitudes, verbal commitment and individual sense of responsibility.

Pro-environmental behaviour can be explained by sociological and psychological factors. Based on the model of Fietkau and Kessel (1981) in Kitzmuller (2013), environmental knowledge is shown to have an indirect effect on pro-environmental behaviour. The task of knowledge is to affect the factor of environmental values and this leads to positive or negative environmental behaviour. Schahn and Giesinger (1993) in Kitzmuller (2013) stated that although there is no direct influence of knowledge, it is a necessary variable because pro-environmental action is only possible if people know what they can or could do. Without knowledge, there will be no chance to act in an environmentally friendly way.

However, there are some studies that claim only a small fraction of pro-environmental behaviour can be linked to environmental knowledge (.Kollmuss and Agyeman, 2002). Kempton et al (1995) in Kollmuss and Agyeman (2002) in their study imply that environmental knowledge per se is not a prerequisite for pro-environmental behaviour. Environmental values do play a role in influencing recycling behaviour or pro-environmental behaviour. Saripah et al (2012) found that environmental values have significant influence on recycling behaviour where the measure of recycling behaviour could be used as a measurement of proenvironmental behaviour. Consumers or household residents who have better environmental values, or who are more pro-environment, would have higher participation in recycling. They further added that cultural differences, especially in terms of environmental knowledge may affect the environmental values of the consumers, which consequently affect the way consumers act or behave.

Price and Pitt (2011) summarised three main variables as acting to influence environmental behaviour. They are environmental values, situational factors and psychological variables. Environmental values are defined as an individual's orientation towards the environment and the natural world. Situational factors are variables representing an individual's situation at a given time may affect their environmental action, such as access to services, age or gender. Psychological variables are those representing personality and perception, traits involving philanthropic and motivation qualities, social pressures, environmental threats and a belief in the benefits of individual actions.

According to Akpan et al (2003), exploring the concept of individual pro-environmental behavior involves basic questions such as: "Is there such a thing as environmental morality?" and if so, "Do humans have inherent sense of environmental mortality, or is it developed as we grow?" Environmental morality here suggests a set of values that translate into a sense of moral obligation in reasoning about human acts that impact the biophysical environment. Those who have strong moral norms are more likely to act on 
environmental knowledge (Barr et al., 2005; Olofsson \& Ohman, 2006). Values are responsible for shaping much of our intrinsic motivation. One way to explore the determining factors that shape environmental values is to study the life experience that shaped the beliefs and values of active environmentalists (Kollmuss and Agyeman, 2002). What determine environmental values in people? According to Chawla (1999), the most influential experience during childhood would be experiences of natural areas and family; during adolescence and early adulthood were education and friends; and during adulthood, it was pro-environmental organizations. Kollmuss and Agyeman (2002) do not attribute a direct relationship to environmental knowledge and pro-environmental behaviour. However, it is posited that the longer the education, the more extensive is the knowledge about environmental issues. After the discussions of the above said literature, three hypotheses have been developed;

$\mathrm{H1}$ : Environmental knowledge has significant and direct effects on pro-environmental behaviour

$\mathrm{H} 2$ : Environmental knowledge has significant and direct effects on environmental value $\mathrm{H} 3$ : environmental value has significant and direct effects on pro-environmental behavior

Theoretically, the endogenous variable is pro-environmental behaviour and the exogenous variable is environmental knowledge. In this study, it is hypothesized that environmental value mediates or intervenes the relationship between environmental knowledge and pro-environmental behaviour. That is, how significant is the role played by environmental value in linking the effect of environmental knowledge on pro-environmental behaviour?

\subsection{Methodology}

The population for this study is the residents of five large urban neighborhoods in Malaysia, namely Kuala Lumpur, Penang, Johor Bahru, Kota Kinabalu and Kuching. These are the five largest cities in Malaysia and all have the provision of recycling facilities. Each city receives services from a different service provider. Kuala Lumpur, the capital of Malaysia is served by Alam Flora Sdn Bhd, Johor Bahru is served by SWM Sdn Bhd, whilst Penang, Kota Kinabalu and Kuching are served by their own town councils. The sampling framework for the study is the areas where there are recycling bins provided. Exclusions are for those areas without the bins. The sample size for this study is 1098, consisting of 260 respondents from Kuala Lumpur, 149 respondents from Johor Bahru, and 251, 137 and 301 for Penang, Kota Kinabalu and Kuching consecutively.

The measurement of pro-environmental behaviour, environmental knowledge and environmental values uses questionnaires as the tool. The structured self-administered questionnaire was designed to measure all three construct in the study. There are two parts 
of the analysis: namely measurement model and structural model. The measurement model for each construct is analyzed for its validity and reliability prior to modeling the structural model. Before data analyses are carried out, data mining and descriptive analysis for demographic variables are done. This is followed by factor analysis, determining the normality of the data, and finally hypotheses are tested. Data is analyzed using structural equation modeling (SEM). The statistical package Analysis of Moment Structures (AMOS) is used to analyze for model fit (Goodness of fit index), predictive power (regression) and significance of paths for the specified model proposed.

\subsection{Results and Discussions}

Descriptive statistics show that the sample is almost equally represented by both genders, which are 45.8 percent males and 54.2 percent females. The majority of the respondents live in medium cost housing and they are from medium-income level. All skewness values lie between-1.0 and 1.0 in the data mining process. Data is considered normally distributed and is therefore acceptable to proceed with the parametric analysis procedure.

\subsection{Analyzing the mediation effect of environmental value}

The study is interested to determine the mediation role of a construct namely environmental value in the relationship between environmental knowledge and pro-environmental behavior. All three constructs involved in this study are latent and they are measured using a set of generated items in a questionnaire. The environmental knowledge is measured using five items; the environmental value is measured using six items, while proenvironmental behaviour is also measured using six items. According to Zainudin (2012), the researcher needs to assess the measurement model for all latent constructs for unidmensionality, validity, and reliability prior to modeling the structural model (SEM).

\subsection{The confirmatory factor analysis: Analyzing the measurement model}

Thus, this study performed the Confirmatory Factor Analysis (CFA) procedure for all latent constructs using the pooled CFA as proposed by Zainudin (2012). The CFA results showed that the measurement model for all constructs surpassed the requirement for unidimensionality, validity, and reliability. For instance the values of Cronbach's Alpha exceeded 0.7 ; the measures of Composite Reliability (CR) exceeded 0.6, and finally the Average Variance Extracted (AVE) exceeded 0.5. More importantly the Fitness Indexes for both the measurement model and structural model have exceeded the required level (Figure1 and Figure 2).

The Fitness Indexes indicate the extent of how fit is the proposed model to the empirical data at hand (Zainudin, 2012). According to Zainudin (2012), SEM requires the RMSEA value lower than 0.08 ; the $\mathrm{CFI}$ index greater than 0.9 ; and the ratio of Chi square/Degree of freedom should be lower than 5.0 . 


\subsection{The structural equation modeling: Analyzing the mediation effect}

Once the latent constructs passed the CFA stage, the study modelled the structural model for further analysis. The study assessed the mediation effect using the method proposed by Zainudin (2012).

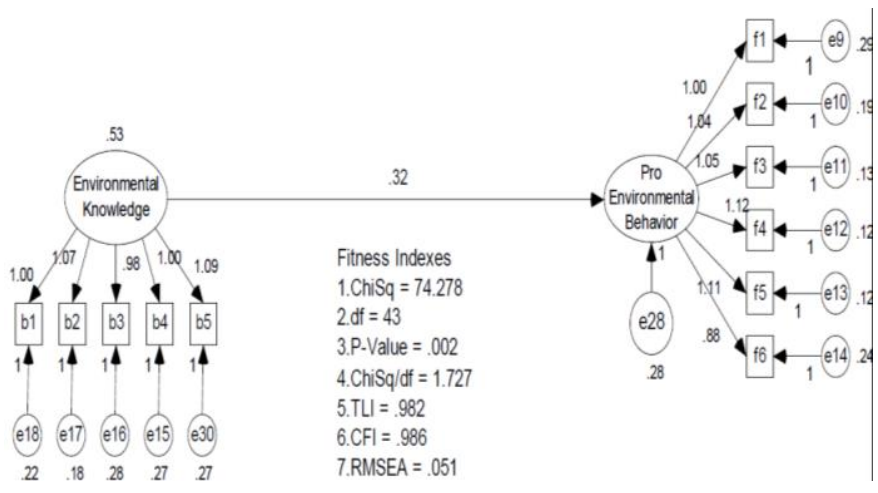

Figure 1: Modeling the direct effect of Environmental Knowledge on Pro Environmental Behavior

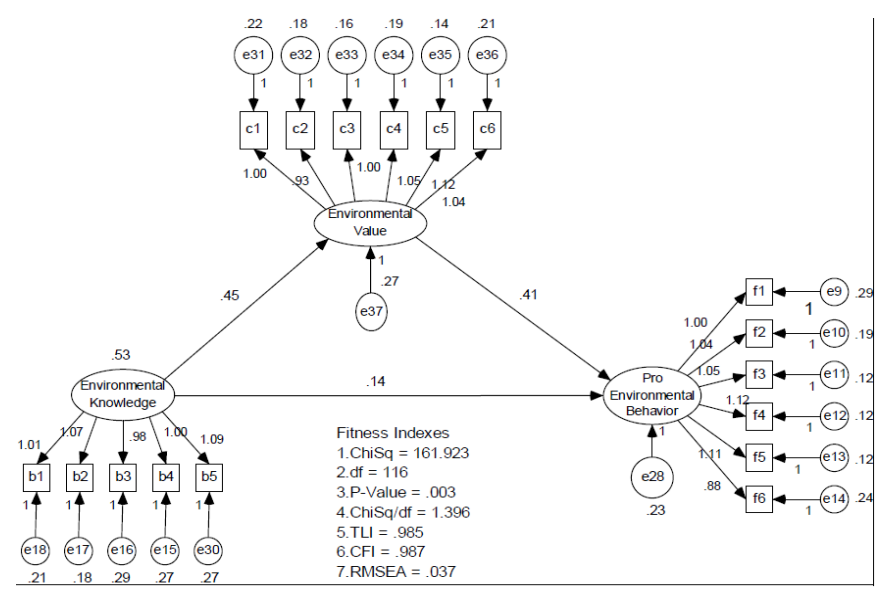

Figure 2: Modelling the environmental values as a mediator linking the environmental knowledge and pro environmental behaviour 
According to Zainudin (2012), there are two effects involved namely direct effect (Figure 1) and indirect effect (Figure 2). Firstly, the direct effect of environmental knowledge on proenvironmental behaviour must exist and be significant. After the mediator environmental value entered the model, the direct effect is reduced. If it reduces but is still significant, then partial mediation occurs. However, if it is no longer significant, then full mediation occurs (Zainudin, 2012).

Referring to Figure 1 , the direct effect of environmental knowledge is significant $\left(\beta_{1}=\right.$ 0.32, P-value<0.001). Thus, the hypothesis that the direct effect of respondents' environmental knowledge on their pro- environmental behaviour is significant has been supported.

Figure 2 shows the mediator construct namely environmental value enters the model. The direct effect of environmental knowledge on pro- environmental value has decreased from 0.32 (Figure 1) to 0.14 (Figure 2). In this case the mediation has been established. The type of mediation would depend on the result of the preceding hypotheses.

It is found that the direct effect of environmental knowledge on pro-environmental value is no longer significant $\left(\beta_{1}=0.14, P\right.$-value $\left.=0.089\right)$ after the mediator entered the model. Thus, the hypothesis that the direct effect of respondents' environmental knowledge on their pro- environmental behaviour is not supported. The effect of environmental knowledge on environmental value is significant $\left(\beta_{3}=0.45, P\right.$-value $\left.<0.001\right)$ and the effect of environmental value on pro- environmental behavior is also significant $\left(\beta_{2}=0.41\right.$, $P$ value $<0.001$ ). Therefore, the type of mediation that exists here is called full mediation. Conclusively, the environmental knowledge of the residents should generate their concern on environmental value so that the pro- environmental behaviour among urban residents at large could be achieved.

\subsection{Conclusion}

This study examines the relation between environmental knowledge and pro-environmental behaviour of the residents in urban areas, with environmental values as the mediator. The layout of the research is put down in two objectives. The first objective of the study is to determine the causal relationship between environmental knowledge and proenvironmental behaviour. Another objective is to enlighten the mediating effect of environmental values between environmental knowledge and pro-environmental behaviour. Subsequently, three hypotheses are posited and tested by using structural equation modeling. The first hypothesis is environmental knowledge has significant and direct effects on pro-environmental behaviour. The second one is environmental knowledge has significant and direct effects on environmental value and the last hypothesis is environmental value has significant and direct effects on pro-environmental behaviour.

The results show that initially the direct effect of environmental knowledge on proenvironmental behaviour is significant. Therefore the first hypothesis is supported. It means 
that environmental knowledge is an antecedent for pro-environmental behaviour. This finding conform to past researches by Kollmuss and Agyeman ( 2002) and Kitzmuller (2013).

However, when environmental value is introduced as the mediator linking the relationship between environmental knowledge and pro-environmental behaviour, the effect of environmental knowledge on pro-environmental behaviour is no longer significant. On the other hand, the effect of environmental knowledge on environmental value and environmental value on pro-environmental behaviour are both significant. Both hypothesis two and hypothesis three are supported. This shows that environmental value is a full mediator for environmental knowledge and pro-environmental behaviour. It means that environmental value intervenes the relationship between environmental knowledge and proenvironmental behaviour. That is why when environmental value enters the model, the direct effect of environmental knowledge on pro-environmental behaviour is no longer significant. This finding is similar to the model proposed by Fietkau and Kessel (1981) and part of the model by Kollmuss and Agyeman (2002). They do not attribute a direct relationship to environmental knowledge and pro-environmental behaviour. Instead it is shown in this study that environmental value mediates the relationship.

The implication here is that environmental educators, city managers and policy makers should pay serious attention to the role of environmental value as the intervening variable between environmental knowledge and pro-environmental behaviour. As Chawla (1999) has pointed out, environmental value of individuals is determined by their experiences. So what kinds of experiences are we going to provide to our people to convert them into proenvironmental residents?

As an avenue for future research it is suggested that community-based social marketing is included in the study of pro-environmental behaviour apart from some other conventional educational strategies.

\section{References}

Ajzen, I. \& Fishbein, M. (1980). Understanding attitudes and predicting $\mathrm{NJ}$, Prentice Hall.

social behaviour, Englewood Cliff,

Akpan, I., Del Matto, T, Hunsberger, C., Rehbein, C., Rogozinski, E., Rosenthal, H. \& Shaw, T. (2003). Strategies for promoting pro-environmental behaviour among University of Waterloo students. University of Waterloo Department of Environment and Resource Studies.

Barr, S., Gilg, A. \& Ford, N. (2005). Conceptualizing and analyzing household attitudes and actions to a growing environmental problem: Development and application of a framework to guide local waste policy. Applied Geography, 25, 226-247.

Chawla, L. (1999). Life paths into effective environmental action. The Journal of Environmental Education, 31(1), 15-26. 
Hu, B., Dong, X. \& Yang, Z. (2013). An empirical study of sustainable consumption behavior among residents in Changsha. Retrieved from www.sciofbluemountain.com/search/detail.php?id=5627

Kitzmuller, C. (2013). Environmental knowledge and willingness to change personal behaviour: An AmericanAustrian comparisons of energy use. Retrieved from www. Unimuenstede/imperia/md/content/transpose/./kitzmueller

Kollmuss, A. \& Agyeman, J. (2002). Mind the gap: why do people act environmentally and what are the barriers to proenvironmental behaviour? Environmental Education Research, 8(3).

Olofsson, A. \& Ohman, S. (2006). General beliefs and environmental concern: Transatlantic comparisons. Environment and Behavior, 38(6), 768-790.

Price, S. \& Pitt, M. (2011). The influence of facilities and environmental values on recycling in an office environment, Indoor and Built Environment. Retrieved from http//ibe.sagepub.com/content/21/5/622.refs.html

Saripah, A. L., Mohd Shukri, O., Yeop Hussin, B. \& Zainudin, A. (2012). Environmental values as a predictor of recycling behaviour in urban areas: A comparative study. Procedia-Social and Behavioral Sciences, 50, 989-996.

Saripah, A. L., Mohd Shukri, O., Yeop Hussin, B. \& Zainudin, A. (2013). Effect of situational factor on recycling behaviour in determining the quality of life. Journal of ASIAN Behavioral Studies, 3(8), 3746.

Saripah, A. L., Yeop Hussin, B. \& Zainudin, A. (2013). Towards the realization of green cities: The moderating role of the Paper presented at ASEAN Conference on Environmental-Behaviour Studies, Hanoi, Vietnam.

Zainudin, A. (2012). Research Methodology and Data Analysis 2nd Edition. Shah Alam: Universiti Teknologi MARA Publication Centre (UiTM Press).

Zainudin, A. (2012). Structural Equation Modeling using Amos Graphic. Shah Alam: Universiti Teknologi MARA Publication Centre (UiTM Press). 